Gynecologic and

Obstetric Investigation
Gynecol Obstet Invest 2011;71:66-72

DOI: $\underline{10.1159 / 000316053}$
Received: March 3, 2010

Accepted after revision: May 31, 2010

Published online: December 15, 2010

\title{
Assessing the Role of the Non-Pneumatic Anti-Shock Garment in Reducing Mortality from Postpartum Hemorrhage in Nigeria
}

\author{
Oladosu A. Ojengbede ${ }^{a}$ Imran Oludare Morhason-Bello ${ }^{a}$ Hadiza Galadancib \\ Carinne Meyer ${ }^{c}$ David Nsima ${ }^{d}$ Carol Camlin ${ }^{c}$ Elizabeth Butrick ${ }^{c}$ \\ Suellen Millerc
}

\begin{abstract}
${ }^{a}$ Center for Population and Reproductive Health, College of Medicine/University College Hospital, University of Ibadan, Ibadan, ${ }^{b}$ Aminu Kano Teaching Hospital, Kano, Nigeria; ${ }^{c}$ Department of Obstetrics, Gynecology and Reproductive Sciences, University of California, San Francisco, Calif., USA; ${ }^{\mathrm{d} D e p a r t m e n t}$ of Obstetrics and Gynecology, Katsina General Hospital, Katsina, Nigeria
\end{abstract}

\section{Key Words}

Non-pneumatic anti-shock garment $\cdot$ Emergency

obstetric care $\cdot$ Maternal morbidity $\cdot$ Maternal mortality •

Postpartum hemorrhage

\begin{abstract}
Background/Aims: Postpartum hemorrhage (PPH) is the leading cause of maternal mortality. The non-pneumatic anti-shock garment (NASG), a first-aid lower-body pressure device, may decrease mortality. Methods: This pre-intervention/NASG study of 288 women was conducted in four referral facilities in Nigeria, 2004-2008. Entry criteria: women with PPH due to uterine atony, retained placenta, ruptured uterus, vaginal or cervical lacerations or placenta accreta with estimated blood loss of $\geq 750 \mathrm{ml}$ and one clinical sign of shock. Differences in demographics, conditions on study entry, treatment and outcomes were examined. $t$ tests and relative risks with $95 \%$ confidence intervals were calculated for primary outcomes - measured blood loss and mortality. Multiple logistic regression analysis was performed to examine independent association of the NASG with mortality. $\boldsymbol{R} \boldsymbol{e}$ sults: Mean measured blood loss decreased by $80 \%$ be-
\end{abstract}

tween phases. Women experienced $350 \mathrm{ml}$ of median blood loss after study entry in the pre-intervention and $50 \mathrm{ml}$ in the NASG phase $(p<0.0001)$. Mortality decreased from $18 \%$ preintervention to $6 \%$ in the NASG phase $(\mathrm{RR}=0.31,95 \% \mathrm{Cl} 0.15-$ $0.64, p=0.0007)$. In a multiple logistic regression model, the NASG was associated with reduced mortality (odds ratio $0.30 ; 95 \% \mathrm{Cl} 0.13-0.68, \mathrm{p}=0.004)$. Conclusion: The NASG shows promise for reducing mortality from $\mathrm{PPH}$ in referral facilities in Nigeria.

Copyright $\odot 2010$ S. Karger AG, Basel

\section{Introduction}

Postpartum hemorrhage ( $\mathrm{PPH})$, blood loss exceeding $500 \mathrm{ml}$ after delivery, is the single largest cause of maternal death worldwide. Most maternal deaths from PPH are preventable with care from a skilled provider. The unique challenges to providing maternal health care in the developing world demonstrate great global inequities. The World Health Organization (WHO) estimates that 150,000 women bleed to death each year from PPH, with over $99 \%$ of these deaths occurring in developing countries [1]. Women in developing countries are more than

\section{KARGER}

Fax +41613061234 E-Mail karger@karger.ch www.karger.com (c) 2010 S. Karger AG, Basel

0378-7346/11/0711-0066\$38.00/0

Accessible online at:

www.karger.com/goi
Suellen Miller

50 Beale Street, Suite 1200

San Francisco, CA 94105 (USA)

Tel. +1 415597 9353, Fax +1 4155979300

E-Mail suellenmiller@gmail.com 
40 times more likely than women in developed countries to die in childbirth (1 in 61 women in developing countries vs. 1 in 2,800 women in developed countries) [2].

In developing countries, many women deliver at home or in their communities in the attendance of a family member or traditional birth attendant. Without a skilled provider present, early signs of complications may not be identified. A woman suffering from PPH can die within $2 \mathrm{~h}$ unless she receives immediate and appropriate medical care [1]. The decision to take the woman to a health facility may be delayed and transportation may not be available. When a woman suffering from PPH arrives at a health facility, there may not be trained staff, essential supplies or medications available to treat her [3].

Etiologies of PPH include uterine atony, retained placenta, ruptured uterus, vaginal/cervical lacerations or placenta accreta. Women suffering from PPH can experience hemorrhagic shock, which occurs when there is hypoperfusion of the vital organs causing deprivation of oxygen to the brain, heart and lungs. Current international standards for the prevention of $\mathrm{PPH}$ include active management of third-stage labor (AMTSL). This protocol, as accepted by the International Confederation of Midwives and the International Federation of Gynecology and Obstetrics, includes the administration of an uterotonic within $5 \mathrm{~min}$ of delivery, controlled cord traction and uterine massage [4]. AMTSL can reduce the risk of PPH by up to $60 \%[5,6]$, but thousands of women still experience hemorrhage and death due in part to lack of knowledge about AMTSL, lack of adherence to AMTSL protocols, delays in treatment and medication stock-outs. In a recent study in 7 tertiary care facilities in Nigeria, complete application of AMTSL was used only $42 \%$ of the time [7]. Even with AMTSL, PPH from uterine atony can occur; further, other etiologies of $\mathrm{PPH}$ are not prevented by AMTSL. Current treatment protocols for PPH and hypovolemic shock include the administration of treatment uterotonics, bimanual massage, manual removal of placenta, repair of lacerations, blood transfusion and surgery. All of these may be unobtainable in low-resource settings, except at tertiary facilities, and women may experience long delays even at these facilities [8].

In low-resource settings where delays in management of PPH occur, first aid is needed to stabilize women and increase their chances of survival until definitive treatment is obtained. The non-pneumatic anti-shock garment (NASG) is a first-aid lower-body pressure device made from neoprene and Velcro ${ }^{\mathrm{TM}}$ (Zoex Corp., Ashland, Oreg., USA) comprised of nine segments which are wrapped tightly around a woman's legs, pelvis and abdo- men. A foam compression ball in the abdomen segment applies focused external pressure to the uterus. The garment is applied sequentially from the ankles upward. This device exerts circumferential pressure on the lower half of the body reducing total vascular space and at the same time increasing the volume of blood in the central circulation, translocating oxygenated blood to the vital organs [9]. These mechanisms of action result in the reversal of hemorrhagic shock and the stabilization of the patient while awaiting transport, during transport, or during delays in receiving care at referral facilities.

In addition to its potential for decreasing adverse outcomes from hypovolemic shock secondary to PPH worldwide, the NASG is uniquely suited for use in developing countries due to its simple design and relatively low cost. Currently, the device costs USD 170 and training for application is relatively brief. After decontamination and laundering, the device can be re-used up to 40 times. Vaginal procedures can be performed with the NASG in place and abdominal surgeries can be conducted by opening the abdominal section for the duration of the surgery.

The utility of the NASG in low-resource referral facilities has been reported in four articles on women with obstetric hemorrhage from all etiologies, including a case series in Pakistan, a pilot pre-intervention/NASG study in Egypt $(\mathrm{n}=364)$, one larger pre-intervention/NASG study in Egypt $(\mathrm{n}=990)$ and one small study from one facility in Nigeria $(n=169)$ [10-14]. In this article, we examine the impact of the NASG on women suffering from $\mathrm{PPH}$ at four referral facilities in Nigeria.

\section{Materials and Methods}

This study is a sub-analysis of a pilot introduction of the NASG with 756 women with obstetric hemorrhage of all etiologies at 12 secondary and tertiary facilities in Nigeria from March 2004 to January 2008. The methods applied have been described in more detail in a previously published study from one facility in Nigeria [14]. For the present PPH subset analysis, we examined only the data on women admitted for PPH at 4 tertiary facilities -2 teaching facilities and 2 state facilities - where there was a relative balance between the number of participants in the pre-intervention and NASG phases. At 8 of the 12 facilities there was no pre-intervention phase, so comparing outcomes from those facilities would be spurious. The average annual deliveries ranged from 5,000 to 10,000 at the state-level facilities and from 1,250 to 2,300 at the university facilities. To be eligible for the study, women presented with PPH and shock, defined by an initial blood loss of $\geq 750 \mathrm{ml}$ and at least one clinical sign of shock (systolic blood pressure $<100$ $\mathrm{mm} \mathrm{Hg}$ or pulse $>100$ beats/min). This article reports study outcomes only for 288 women suffering from PPH diagnoses which include uterine atony, retained placenta or tissue, ruptured uter- 
us, vaginal/cervical lacerations and placenta accreta. During the pre-intervention phase, women were treated with standard shock and hemorrhage management; during the intervention phase the NASG was added to the standard protocol. All facilities adopted the same evidence-based standardized protocol.

After an explanation of study aims, all pre-intervention study participants gave verbal consent, and all NASG participants gave written consent to the use of the NASG. A United States Federal waiver of consent/authorization for minimal-risk research (45 CFR 46, 45 CFR 164.512) was obtained so that women who were unconscious or confused at the time of study entry were enrolled in the study without consent; permission to use their data was given through written consent once the patient returned to normal sensorium or a relative gave consent on their behalf. The University of California, San Francisco (UCSF) Committee on $\mathrm{Hu}$ man Research (approval No. H6899-23524) and the National Reproductive Health Research Committee of the Nigeria Federal Ministry of Health gave ethical approval for the study.

All study participants in both phases had blood loss measured with a calibrated blood collection drape (BRASS-V Fixable Drape $^{\mathrm{TM}}$, Madurai, India), which was placed under them for the accurate measurement of blood loss after study entry. The evidence-based protocol for the treatment of PPH included administration of crystalloid intravenous fluids $(\geq 1,500 \mathrm{ml}$ in the first hour), uterotonic medications (oxytocin, ergometrine, syntometrine, misoprostol), uterine massage for patients with uterine atony, vaginal procedures (bimanual compression, manual removal of placenta or dilation, repair of lacerations and curettage for retained tissue) and abdominal surgeries (arterial ligation, B-Lynch compression sutures, hysterectomy) as necessary.

In the NASG phase, the NASG was applied at the time of study admission and remained in place for the duration of the study. The NASG is always applied in the same way, regardless of etiology. The NASG is applied starting at the ankles with segment No. 1 , next segment No. 2 is applied to both calves, and then segment No. 3 is applied to both thighs. One person using all their strength then applies segment 4 completely around the woman at the level of the pubic bone, and then sections 5 and 6 which contains the pressure ball are tightened over the umbilicus. The NASG is simple to apply and all clinicians were trained in a hands-on training session. There were no reports of misapplications. The abdominal section was removed during surgeries prior to the first incision and re-applied immediately after surgery completion. All patients were monitored closely until they were stable, and study discharge and NASG removal time were determined by $2 \mathrm{~h}$ of hemodynamic stability (systolic blood pressure $>100 \mathrm{~mm} \mathrm{Hg}$ and pulse $<100$ beats/min). The device was then sequentially opened starting at the ankles with 15-min intervals between segments. If during removal the woman's blood pressure fell by $20 \mathrm{~mm} \mathrm{Hg}$ or pulse increased by 20 beats/min, all segments would be immediately reapplied.

Clinician data collectors were trained in the standard management of shock and PPH, collection and measurement of blood loss and completion of data collection forms. These staff monitored and recorded vital signs, level of consciousness, urine output and blood loss. Data forms were reviewed by data supervisors and the Nigerian Principal Investigators. Data were entered into a Microsoft Access database (Microsoft, Redmond, Wash., USA), checked for errors and inconsistencies and analyzed at UCSF.
The condition of patients on study entry was calculated using mean arterial pressure $(\mathrm{MAP}=[2 \cdot$ diastolic blood pressure $]+$ systolic blood pressure/3) [15]. Primary outcomes included cumulative median blood loss measured in the drape and mortality. Tests of significance of differences by study phase were $\chi^{2}$ for categorical variables, $t$ tests (assuming unequal variances) for normally-distributed continuous variables and Wilcoxon rank-sum tests for non-normal distributions.

To estimate the independent effect of the NASG, we used a multiple logistic regression model to control for other characteristics which might predict mortality. The independent variables included in the model were selected on the basis of their prior significance in the literature on maternal mortality and for significant association (at the $95 \%$ confidence level) with mortality in bivariate analyses. Variables selected were high parity, MAP $<60$, type of facility (university or state) and study phase. Data were analyzed using STATA Version 10 (StataCorp, College Station, Tex., USA).

\section{Results}

A total of 288 women were included in the analysis of which 114 were in the pre-intervention phase and 174 in the NASG phase. The demographic characteristics of the participants in the two phases are shown in table 1 . There were no statistically significant differences between the pre-intervention and NASG phases with respect to age, duration of pregnancy, most hemorrhage etiologies and conditions on study entry. Women in the pre-intervention phase had higher median parity (6 vs. $4, \mathrm{p}=0.010)$ and fewer women had vaginal/cervical lacerations ( $2.6 \mathrm{vs.}$ $12.6 \%, \mathrm{p}=0.002)$. The majority $(72.9 \%, \mathrm{n}=210)$ of all 288 women in both phases were in severe shock with MAP $<60 \mathrm{~mm} \mathrm{Hg}, \mathrm{n}=77$ (67.5\%) pre-intervention versus $\mathrm{n}=$ 133 (76.9\%) NASG phase; these results were not significantly different.

During both phases, women received comparable treatment as shown in table 2 , although all women experienced delays in receiving treatment. There were no statistically significant differences between administration of treatment uterotonics for women with a primary or secondary diagnosis of uterine atony, receipt of blood transfusion in the first hour or blood transfusion at any time during the study. There was a higher proportion of women who received $\geq 1,500 \mathrm{ml}$ of intravenous fluids in the first hour in the intervention group which was marginally significant.

Women in the NASG phase experienced better outcomes as demonstrated in table 3. Mean measured blood loss decreased by $80 \%$ between phases. Women experienced $350 \mathrm{ml}$ of median blood loss after study entry in the pre-intervention and $50 \mathrm{ml}$ in the NASG phase $(\mathrm{p}<$ 
Table 1. Demographics, diagnoses, and conditions on entry to study

\begin{tabular}{|c|c|c|c|}
\hline Characteristic & Pre-intervention $(\mathrm{n}=114)$ & NASG $(n=174)$ & $\mathrm{p}$ value \\
\hline Age, years ${ }^{\mathrm{a}}$ & $29.4(6.7)$ & $30.2(6.5)$ & 0.338 \\
\hline Mean parity, births ${ }^{\mathrm{b}}$ & $5.7(3.4)$ & $4.7(3.5)$ & - \\
\hline Median parity, IQR & $6(3-8)$ & $4(2-7)$ & 0.010 \\
\hline Duration of pregnancy, weeks ${ }^{c}$ & $38.0(2.8)$ & $37.6(3.1)$ & - \\
\hline Median weeks, IQR & $38(37.5-40)$ & $38(37-40)$ & 0.242 \\
\hline \multicolumn{4}{|l|}{ Definitive diagnosis } \\
\hline Uterine atony & $42(36.8)$ & $73(42.0)$ & 0.386 \\
\hline Retained placenta or tissue & $52(45.6)$ & $63(36.2)$ & 0.111 \\
\hline Ruptured uterus & $16(14.0)$ & $14(8.1)$ & 0.104 \\
\hline Vaginal/cervical lacerations & $3(2.6)$ & $22(12.6)$ & $0.002^{\mathrm{d}}$ \\
\hline Placenta accreta & $1(0.9)$ & $2(1.2)$ & $1.000^{\mathrm{d}}$ \\
\hline \multicolumn{4}{|l|}{ Condition on study entry } \\
\hline \multicolumn{4}{|l|}{ Estimated blood loss, ml } \\
\hline Mean blood loss ${ }^{\mathrm{e}}$ & $1,350.5(512.8)$ & $1,468.2(572.8)$ & - \\
\hline Median blood loss, IQR & $1,500(1,000-1,500)$ & $1,500(1,000-2,000)$ & 0.086 \\
\hline Women with MAP $<60 \mathrm{~mm} \mathrm{Hg}^{\mathrm{f}}$ & $77(67.5)$ & $133(76.9)$ & 0.081 \\
\hline \multicolumn{4}{|c|}{$\begin{array}{l}\text { NASG }=\text { Non-pneumatic anti-shock garment; IQR }=\text { interquartile range; } \mathrm{ml}=\text { millimeters; MAP }=\text { mean } \\
\text { arterial pressure. Data are } \mathrm{n}(\text { column } \%) \text {, mean }(\mathrm{SD}) \text { or median }(\mathrm{IQR}) \text {. The denominator is the entire population, } \\
\text { unless otherwise noted. Tests of significance of differences by study phase were } \chi^{2} \text { for categorical variables, } \\
\text { t tests (assuming unequal variances) for normally-distributed continuous variables and Wilcoxon rank-sum } \\
\text { tests for non-normal distributions. } \\
{ }^{a} \text { Data are missing for } 2 \text { women. }{ }^{\mathrm{b}} \text { Data are missing for } 7 \text { women. }{ }^{\mathrm{c}} \text { Data are missing for } 25 \text { women. Does not } \\
\text { include pregnancies }<24 \text { weeks. }{ }^{\mathrm{d}} \text { Fisher's exact test used. }{ }^{\mathrm{e}} \text { Data missing for } 11 \text { women. }{ }^{\mathrm{f}} \mathrm{MAP}<60 \mathrm{~mm} \mathrm{Hg} \text { cat- } \\
\text { egory includes those with non-palpable blood pressure. Data missing for } 1 \text { woman in the NASG group. }\end{array}$} \\
\hline
\end{tabular}

Table 2. Treatments for shock and hemorrhage administered during two study phases

\begin{tabular}{lcrc}
\hline Treatment & Pre-intervention $(\mathrm{n}=114)$ & NASG $(\mathrm{n}=174)$ & $\mathrm{p}$ value \\
\hline Any treatment uterotonics & $46 / 49(93.9)$ & $74 / 81(91.4)$ & $0.601^{\mathrm{a}}$ \\
$\geq 1,500 \mathrm{ml}$ crystalloid IV fluids in 1st hour & $55(48.3)$ & $104(59.8)$ & 0.054 \\
Blood transfusion in 1st hour & $12(10.5)$ & $25(14.4)$ & 0.341 \\
Blood transfusion during study & $92(80.7)$ & $145(83.3)$ & 0.567 \\
\hline
\end{tabular}

NASG = Non-pneumatic anti-shock garment; $\mathrm{ml}=$ milliliters; $\mathrm{IV}=$ intravenous. Data are $\mathrm{n}=$ number of women in each phase and \% of total in each phase. The denominator is the entire population, unless otherwise noted. Since the treatments are independent, there is no column total.

Tests of significance of differences by study phase were $\chi^{2}$ for categorical variables.

${ }^{a}$ For women with uterine atony as primary or secondary diagnosis. Data are for 130 cases. Fisher's exact test used.

0.0001). There was a statistically significant decrease in the percentage of women who died from PPH; 21 (18.4\%) women died in the pre-intervention phase versus 10 (5.8\%) women in the NASG phase $(\mathrm{RR}=0.31 ; 95 \% \mathrm{CI}$ $0.15-0.64, \mathrm{p}=0.0007)$.
In bivariate analyses ( $t$ tests and logistic regression) the following variables, in addition to study phase, were found to be significantly associated with mortality at the 95\% confidence level: parity, severity of shock and type of facility. Using a multiple logistic regression model that 
Table 3. Outcomes between standard hemorrhage and shock management (pre-intervention) and standard management plus NASG

\begin{tabular}{|c|c|c|c|c|}
\hline Outcome & Pre-intervention $(\mathrm{n}=114)$ & NASG $(n=174)$ & Relative risk (95\%CI) & $\mathrm{p}$ value \\
\hline Mean measured vaginal blood loss in drape, $\mathrm{ml}^{\mathrm{a}}$ & $470.6(404.6)$ & $94.9(110.9)$ & - & - \\
\hline Median measured blood loss, IQR & $350(200-620)$ & $50(0-160)$ & - & $<0.0001$ \\
\hline Mortality & $21(18.4)$ & $10(5.8)$ & $0.31(0.15-0.64)$ & 0.0007 \\
\hline
\end{tabular}

NASG = Non-pneumatic anti-shock garment; IQR = interquartile range. Data are $\mathrm{n}$ (column \%) or mean (SD). The denominator is the entire population, unless otherwise noted. Wilcoxon rank sum tests used to test for association with study phase for non-normally distributed variables.

${ }^{a}$ For cases in which the calibrated blood collection drape was used and there were data for blood loss. Data are for 192 cases.

Table 4. Multiple logistic regression model of factors predictive of mortality $(\mathrm{n}=288)$

\begin{tabular}{llll}
\hline Dependent variable: mortality & OR & p & $95 \%$ CI \\
\hline $\begin{array}{l}\text { Parity } \\
\quad \begin{array}{l}\text { or more live births } \\
\text { 0-4 live births }\end{array}\end{array}$ & 0.91 & 0.814 & $0.40-2.06$ \\
$\begin{array}{l}\text { Severity of shock } \\
\quad \text { MAP }<60 \text { (or non-palpable }\end{array}$ & 6.84 & 0.011 & $1.55-30.19$ \\
$\quad$ blood pressure) & & & \\
$\quad \begin{array}{l}\text { MAP 60 or higher } \\
\text { Type of facility }\end{array}$ & 1 & & \\
$\quad \begin{array}{l}\text { University hospital } \\
\text { Non-university hospital }\end{array}$ & 0.26 & 0.081 & $0.06-1.18$ \\
$\begin{array}{l}\text { Study phase } \\
\quad \text { NASG }\end{array}$ & 1 & & \\
$\quad$ Pre-intervention & 0.30 & 0.004 & $0.13-0.68$ \\
\hline
\end{tabular}

MAP = Mean arterial pressure; NASG $=$ non-pneumatic antishock garment; IV = intravenous. Reference groups for categorical variables are shown in italics.

included these variables, we estimated the independent effect of the NASG intervention on mortality controlling for other characteristics predictive of mortality. In the multiple regression model, severity of condition upon study admission was strongly associated with mortality after controlling for other variables in the model: high parity, study phase and type of facility (university facility vs. state). Women with MAP $<60 \mathrm{~mm} \mathrm{Hg}$ had over 6 times the odds of mortality (odds ratio [OR] 6.84; 95\% CI, 1.55-30.19). High parity and type of facility were not significantly associated with mortality in the adjusted model. The NASG remained significantly associated with reduced odds of mortality (OR 0.30; 95\% CI 0.13-0.68, p = 0.004) (table 4).
Because of the very strong association of MAP $<60$ with mortality, we ran a stratified analysis of the effect of MAP $<60$ on outcome by phase. In this analysis the NASG significantly improved outcomes for those with both more and with less severe shock. Of the 210 women with MAP $<60$, the percentage of women dying was $24.7 \%(\mathrm{n}=19)$ in the pre-intervention phase versus $7.5 \%$ $(\mathrm{n}=10)$ in the NASG phase, OR $=0.25$ (95\% CI 0.10-0.61). While the rate of mortality was far lower for those with MAP $>60$ in both the pre- and intervention phases, those in the NASG group still had better outcomes, with none dying during the NASG phase, while 3.6\% $(\mathrm{n}=2)$ died in the pre-intervention phase (table 5).

\section{Discussion}

$\mathrm{PPH}$ is a life-threatening condition globally and is the cause of $25 \%$ of maternal deaths in Nigeria, where the maternal mortality ratio is 1,100 deaths per 100,000 live births [16]. The use of the NASG as part of standard management of $\mathrm{PPH}$ and hypovolemic shock at four referral facilities in Nigeria was associated with a significant reduction in blood loss and maternal mortality even when controlling for severity of shock at study entry, parity, and the type of facility.

The NASG significantly reduced mortality even among women who were in severe shock, which is very encouraging. However, $7.5 \%$ of women who received the NASG and who had MAP $<60$ on study entry did die. This reinforces our message that the NASG is first aid only; while it can resuscitate women in shock, it is not definitive treatment. Without blood, crystalloid fluids, and comprehensive emergency obstetric care, some women, despite first aid with the NASG, will die from hypovolemic shock. 
Table 5. Effect of NASG on mortality by severity of condition ( $\mathrm{n}=288$ women, 31 mortalities)

\begin{tabular}{llll}
\hline & $\begin{array}{l}\text { Pre-intervention, } \mathrm{n} / \mathrm{N} \\
(\mathrm{n}=114) 21 \text { mortalities }\end{array}$ & $\begin{array}{l}\text { NASG, } \mathrm{n} / \mathrm{N}(\mathrm{n}=174) \\
10 \text { mortalities }\end{array}$ & $\begin{array}{l}\text { OR } \\
(95 \% \mathrm{CI})\end{array}$ \\
\hline $\begin{array}{l}\mathrm{MAP} \geq 60(\mathrm{n}=78)^{\mathrm{a}} \\
2 \text { mortalities }\end{array}$ & $2 / 56(3.6 \%)$ & $0 / 32(0 \%)$ & $\mathrm{NS}$ \\
\hline $\begin{array}{l}\text { MAP }<60(\mathrm{n}=210)^{\mathrm{b}} \\
29 \text { mortalities }\end{array}$ & $19 / 77(24.7 \%)$ & $10 / 133(7.5 \%)$ & $0.25(0.10-0.61)$ \\
\hline
\end{tabular}

MAP $=$ Mean arterial pressure; NASG $=$ non-pneumatic anti-shock garment.

${ }^{a}$ Of the 77 women with MAP $\geq 60$, there were 56 cases in the pre-intervention group and 40 cases in the NASG group. ${ }^{\mathrm{b}}$ Of the 210 women with $\mathrm{MAP}<60$, there were 77 cases in the pre-intervention group and 133 cases in the NASG group.

Limitations to this study are associated with the preintervention/intervention, non-randomized design. Specific limitations include the possibility of selection bias, which may have occurred as eligibility criteria and clinicians influence limited entry into the study. Despite this limitation, there were few statistically significant differences in demographics and treatment variables during the two phases and our regression analysis aims to control for such imbalances between phases. Another limitation is associated with the temporal non-concurrence of the phases. Over the study period, the study clinicians skill level may have improved as a result of the frequent trainings and more diligent practice of the evidencebased protocol; for example, the increased percentage of women who received $\geq 1,500 \mathrm{ml}$ of intravenous fluids in the first hour between the two phases may have been due to improved adherence to protocols over the study period. Further, research in understaffed and overburdened hospitals in low-resource settings can result in barriers to protocol adherence and data collection. Finally, many women in Nigeria die before they reach a facility; women who did not present at a facility could not be included in this study, so we cannot generalize beyond the referral facility level.

An interesting difference in the facilities existed between the university hospitals and the state referral hospitals, as evidenced by the protective, but not significant effect of type of facility in the multiple logistic regression model. Although all facilities were capable of comprehensive emergency obstetric care, the university-affiliated hospitals were better equipped with more ready access to blood for transfusions. Further, the number of deliveries was higher at the state facilities while the staff-to-patient ratio was lower; therefore, emergencies may have been responded to more quickly at the university facilities.

The NASG appears to have a role to play as the first-aid treatment for and in the reduction of mortality from $\mathrm{PPH}$ at the referral facility level. Current PPH prevention strategies such as AMTSL and treatment strategies such as administration of uterotonics may not be adequate to address all $\mathrm{PPH}$ from uterine atony. In addition, uterotonics will not address non-atonic etiologies such as lacerations or ruptured uterus. In this study, uterine atony made up only about $40 \%$ of all PPH etiologies, whereas in the literature figures can be as high as 70\% [17]. In many lowresource settings there is currently no treatment for hypovolemic shock during long delays prior to obtaining definitive treatment. Even in the study referral facilities, approximately $13 \%$ of women received a blood transfusion in the first hour. Thus, the NASG could buy women time during these delays.

The results of this study indicate that the NASG may be useful for decreasing mortality from $\mathrm{PPH}$, particularly in low-resource settings, when added to well-conducted AMTSL and evidence-based hemorrhage and hypovolemic shock protocols. The NASG's simple and inexpensive design offers distinct advantages for use as a first-aid device in low-resource referral facility settings. These findings show promise for saving women's lives from PPH and add to a growing body of knowledge about the NASG for all etiologies of obstetric hemorrhage from previous studies in Pakistan, Egypt and Nigeria [12-14].

Maternal mortality is a global public health problem and was adopted as a Millennium Development Goal by 189 nations at the UN Millennium Summit in September 2000 [18]. Despite these commitments, the world's maternal mortality remains extremely high with estimates 
from 342,900 to 500,000 women dying in childbirth each year [19]. Most low-resource countries do not appear ready to meet Millennium Development Goal \#5, the reduction of maternal mortality by $75 \%$ by 2015 . New strategies and technologies are needed if there is to be a meaningful reduction in global maternal mortality. While this study indicates the utility of the NASG at the referral facility, in many high maternal mortality rate countries, births occur at home attended by unskilled birth attendants or family members. Therefore, the next step is to evaluate the efficacy of early application of the NASG at the clinic level where it is hypothesized that the NASG will have an even greater impact.

\section{Acknowledgements}

The authors thank the clinician data collectors and project data supervisors at all four sites, and also Hilarie Martin, Kemi Role, Titiola Duro-Aina, Lyndsay McDonough, Janet Turan, Dr. Paul Hensleigh and the Federal Ministry of Health, Abuja, Nigeria.

\section{References}

1 World Health Organization: The World Health Report 2005 - Make Every Mother and Child Count. Geneva, WHO, 2005.

2 World Health Organization: Managing Complications in Pregnancy and Childbirth: A Guide for Midwives and Doctors. WHO/ RHR/00.7. Geneva, WHO, 2000.

3 McCarthy J, Maine D: A framework for analyzing the determinants of maternal mortality. Stud Fam Plann 1992;23:23-33.

-4 Armbruster D: Prevention of postpartum hemorrhage: the role of active management of the third stage of labor. Int J Gynaecol Obstet 2006;94:S122-S123.

5 Prendiville WJ, Elbourne D, McDonald S: Active versus expectant management in the third stage of labour. Cochrane Database Syst Rev 2002;1.

-6 Derman RJ, Kodkany S, Goudar SS, Geller SE, Naik VA, Bellad MB, Patted SS, Patel A, Edlavitch SA, Hartwell T, Chakraborty H, Moss N: Oral misoprostol in preventing postpartum haemorrhage in resource-poor communities: a randomised controlled trial. Lancet 2006;368:1248-1253.

7 Oladapo OT, Akinola OI, Fawole AO, Adeyemi AS, Adegbola O, Loto OM, Fabamwo AO, Alao MO, Sotunsa JO, for the Nigerian AMTSL Group: Active management of third stage of labor: evidence versus practice. Acta Obstet Gynecol Scand 2009;88:1252-1260.
8 Lalonde A, Daviss BA, Acosta A, Herschderfer K: Postpartum hemorrhage today: ICM/ FIGO initiative 2004-2006. Int J Gynaecol Obstet 2006;94:243-253.

-9 Miller S, Martin H, Morris JL: Anti-shock garment in postpartum haemorrhage. Best Pract Res Clin Obstet Gynaecol 2008;22: 1057-1074.

10 Brees C, Hensleigh PA, Miller S, Pelligra R: A non-inflatable anti-shock garment for obstetric hemorrhage. Int J Gynaecol Obstet 2004;87:119-124.

$\checkmark 11$ Hensleigh PA: Anti-shock garment provides resuscitation and haemostasis for obstetric hemorrhage. BJOG 2002;109:1377-1384.

$>12$ Miller S, Hamza S, Bray EH, Lester F, Nada K, Gibson R, Fathalla M, Mourad M, Fathy A, Turan JM, Dau KQ, Nasshar I, Elshair I, Hensleigh P: First aid for obstetrical hemorrhage: the pilot study of the non-pneumatic anti-shock garment (NASG) in Egypt. BJOG 2006;113:424-429.

13 Miller S, Turan JM, Dau K, Fathalla M, Mou$\operatorname{rad} \mathrm{M}$, Sutherland T, Hamza S, Lester F, Gibson EB, Gipson R, Nada K, Hensleigh P: Use of the non-pneumatic anti-shock garment (NASG) to reduce blood loss and time to recovery from shock for women with obstetric hemorrhage in Egypt. Glob Public Health 2007;2:110-124.
14 Miller S, Ojengbede O, Turan J, MorhasonBello IO, Martin H, Nsima D: A comparative study of the non-pneumatic anti-shock garment for the treatment of obstetric hemorrhage in Nigeria. Int J Gynecol Obstet 2009; 107:121-125.

15 McAuley DF: The Clinician's Ultimate Reference: Mean Arterial Pressure. GlobalRPh 2007. Available at: http://www.globalrph. com/map.htm (accessed January 4, 2010).

16 Statistics and Indicators of ICPD in Nigeria, UNFPA website. Available at: http://nigeria. unfpa.org/icpdstatistics.htm (accessed January 4, 2010)

17 Bibi S, Danish N, Fawad A, Jamil M: An audit of primary post-partum hemorrhage. J Ayub Med Coll Abbottabad 2007;19:102-106.

18 About the Millennium Development Goals, OECD Development Co-operation Directorate website, retrieved 28 December 2009.

19 Hogan MC, Foreman KJ, Naghavi M, Ahn SY, Wang M, Makela SM, Lopez AD, Lozano R, Murray CJL: Maternal mortality for 181 countries, 1980-2008: a systematic analysis of progress towards Millennium Development Goal 5. Lancet 2010 (in press). 